\title{
RECONHECIMENTO DOS MARCADORES PROSÓDICOS DA ESCRITA EM SITUAÇÃO DE LEITURA E DE OITIVA: UM PROCESSO INTERATIVO
}

\section{RECOGNITION OF THE WRITTEN'S PROSODY MARKERS IN THE SITUATION OF READING AND LISTENING: AN INTERATIVE PROCESS}

\author{
Vera Pacheco* \\ Marian Oliveira ${ }^{* *}$
}

RESUMO: Um texto escrito possui palavras que indicam modos de falar e recursos gráficos que suscitam variações prosódicas e por isso funcionam com marcadores prosódicos. Entendemos que esses marcadores prosódicos possuem dupla realidade: forma escrita e forma auditiva. Diante disso, supomos que o seu reconhecimento deva ser diferente das demais palavras escritas em um texto, requerendo uma arquitetura dos sistemas perceptuais que contemple o seu aspecto visual e auditivo e sua natureza prosódica com acesso interativo às informações contidas nesses sistemas.

PALAVRAS-CHAVE: Marcadores prosódicos. Processo interativo.

Leitura e oitiva de texto.

ABSTRACT: A written text contains words that indicate ways of speaking and graphic recourses to indicate prosodic variations. These markers are called prosodic markers. We understand that these markers have dual reality: the written reality and the auditive reality form. Therefore, we assume that its recognition should be different from the other words in a written text, requiring a differentiated architecture of perceptual systems. Based on experimental data, we conclude that this recognition occurs through the iterative process, in an architecture of perceptual systems covering its visual and auditive aspect and its prosodic nature.

KEYWORDS: Prosody markers. Interative process. Reading. Listening.

\footnotetext{
* Doutora em Linguística (UNICAMP) e Professora do Programa de Pós-graduação em Linguística PPGLin, Universidade Estadual do Sudoeste da Bahia. Vitória da Conquista, Bahia.

${ }^{* *}$ Doutora em Linguística (UNICAMP) e Professora do Programa de Pós-graduação em Linguística PPGLin, Universidade Estadual do Sudoeste da Bahia. Vitória da Conquista, Bahia.
} 


\section{RECONHECIMENTO DOS MARCADORES PROSÓDICOS DA ESCRITA EM SITUAÇÃO DE LEITURA E DE OITIVA: UM PROCESSO INTERATIVO}

\section{OS MARCADORES PROSÓDICOS DA ESCRITA: A INTERFACE ORALIDADE E ESCRITA}

É praticamente indiscutível que a capacidade inata de falar e de expressar seus sentimentos dá ao homem um lugar de destaque entre os animais da natureza. Além dessa capacidade inata, em algumas culturas, o homem, ao longo de sua história, desenvolveu a escrita que, para Whitney (1875, apud MACHADO FILHO, 1974, p.105), decorre "do forte desejo de comunicar à distância, de libertar a expressão de sua natural limitação à presença daquele cujo pensamento é expresso, e torná-la apreensível por pessoas afastadas".

Muito embora hoje, em nossa cultura, escrever nos pareça uma atividade natural $^{1}$ e imprescindível; para que chegássemos ao estágio de progresso condizente com a representação do pensamento por meio de sinais visíveis, a humanidade percorreu um longo caminho (LANGACKER, 1972).

Ao escrever um texto, sempre temos a intenção de expressarmos nossas ideias. Para isso, somos bastante criativos e escolhemos certas palavras em detrimento de outras, usamos um tipo específico de formatação do texto, selecionamos adequadamente os sinais de pontuação.

Dessa forma, temos, de um lado, a intenção do autor e, do outro, a interpretação do leitor, que se dá pelo ato da leitura e que pode ou não coincidir com a intenção do autor.

Do ponto de vista estritamente da literatura clássica a leitura "é o grão de sésamo, o pão para o espírito e o remédio contra a ignorância do povo, o tesouro

\footnotetext{
${ }^{1}$ Vale ressaltar que essa "naturalidade" refere-se à escrita como mais uma possibilidade de comunicação entre os indivíduos, sem entrar no mérito do processo de alfabetização, que ainda não é natural, havendo um número grande de analfabetos no Brasil e no mundo.
} 
escondido da educação social" (MOURÃO, 1998, p.6). Já do ponto de vista da psicolinguística, a leitura é um processo complexo que envolve várias etapas. De acordo com Leffa (1996), o ato de leitura se realiza a partir de múltiplos processos que ocorrem tanto simultânea quanto sequencialmente, de modo a interagir texto e leitor que, juntos, constituem uma engrenagem.

Cagliari (1989) também afirma que, do ponto de vista estritamente da leitura, a maior tarefa é a de decifrar palavras. No entanto, segundo esse autor, isso não é tudo quando se trata de recuperar integralmente o que texto oferece. O leitor precisa concatenar as palavras em unidades maiores (fonológicas, sintáticas, semânticas, discursivas, etc.).

A tarefa de concatenação em unidades maiores é favorecida por recursos gráficos presentes no texto, como o uso de letras maiúsculas, pontos finais, travessão, vírgulas, aspas, pontos de exclamação, interrogação, uso de negrito, itálico, etc. Além disso, há referências ao modo de falar, tais como "disse", "tagarelou", "murmurou", etc. que permitem ao leitor caracterizar a fala dos personagens, aproximando-o do que seria a fala real, recuperando elementos como a qualidade de voz (CAGLIARI,1989).

Para Cagliari (1989) esses recursos gráficos constituem marcadores prosódicos que são classificados por Pacheco (2007a) como marcadores prosódicos gráficos (MPGs), no caso dos sinais de pontuação, e marcadores prosódicos lexicais (MPLs), no caso de palavras que fazem referência ao modo de falar.

Os MPGs, segundo Pacheco (2007a), são todos os sinais de pontuação: ponto final, vírgula, ponto e vírgula, exclamação, interrogação, reticências e os MPLs são palavras que fazem referência ao modo de falar como por exemplo: gritar, sussurrar, falar lentamente, rapidamente, em tom alto, em tom baixo, entre outros.

Ao ler um texto em voz alta, o leitor fluente marca prosodicamente essas pistas gráficas como mostra Pacheco (2003 e 2007b), bem como consegue reconhecer, ao ouvir a leitura de um texto, variações melódicas e associá-las aos usos convencionais dos sinais de pontuação, quando é o caso (PACHECO, 2003).

Pacheco (2007a), tendo como objeto de estudo os MPGs e os MPLs, propõe investigar se o leitor/ouvinte é capaz de reconhecer variações prosódicas e representálas graficamente ao ouvir um texto lido em voz alta e se é igualmente capaz de depreender essas variações a partir da leitura silenciosa. Para isso, a autora avalia, por meio de tarefas aplicadas a onze sujeitos, duas condições experimentais mono modais: 1) apresentação de gravações de leitura oral de textos diversos, condição de somente estímulo auditivo e 2) apresentação do texto escrito para leitura silenciosa, condição somente de estímulo visual.

Com vista a avaliar qual estímulo (visual ou auditivo) era mais preponderante no reconhecimento dos MPGs e dos MPLs, a autora avaliou condições experimentais bi modais com mismatch, que consistiu na apresentação de informações prosódicas não coincidentes no estímulo visual e no estímulo auditivo e sem mismatch, apresentação de informações prosódicas coincidentes no estímulo visual e no estímulo auditivo.

Diante dessas condições experimentais, verificou-se que $i$ ) a leitura silenciosa de um texto evoca mentalmente variações prosódicas incitadas pelos MPGs e MPLs e ii) em condições de duplo estímulo, os MPLs são percebidos exclusivamente pelas informações provenientes do estímulo auditivo e que para os MPGs há uma integração entre as informações prosódicas auditivas e visuais.

Diante disso, podemos afirmar que as palavras que indicam o modo de falar apresentam dois níveis de informações: a) informação segmental, que explicita qual a 
sua constituição em termos de combinação de vogais e consoantes, que pode ser expressa tanto na forma auditiva quanto na forma visual, quando apresentada sob a forma impressa; e, b) informação prosódica, que explicita quais variações melódicas são determinadas por sua carga semântica, como, por exemplo, aumento de volume, velocidade rápida, etc., o que deve ser expresso necessária e exclusivamente na forma oral e auditiva.

Os sinais de pontuação, por seu turno, diferentemente das palavras que indicam modo de falar que podem ser acessadas pela forma auditiva e escrita, são apresentados ao indivíduo somente sob a forma escrita e, dessa forma, apresentados obrigatoriamente sob a forma visual. Mas não podemos perder de vista o fato de a presença de um sinal de pontuação incitar variações melódicas no enunciado que está sob o seu escopo.

Diante do fato de os marcadores prosódicos da escrita possuírem uma realidade escrita, mas ao mesmo tempo uma realidade oral e auditiva, o que não ocorre com todas as palavras que constituem um texto, perguntamo-nos como ocorre o processamento desses importantes elementos textuais na leitura. Estamos diante de um processo topdown ou bottom-up? Seu processamento segue os mesmos sistemas perceptuais encontrados na arquitetura do processamento da fala e da leitura?

Apesar da importância desses elementos textuais na constituição do sentido de um texto, salvo engano, não há registros na literatura de como ocorre o processamento desses marcadores durante a leitura. Falta-nos ainda compreender de que maneira o leitor acessa, ao mesmo tempo, informações tipicamente da língua oral e da língua escrita.

Nossa hipótese é a de que, dado ao fato de esses marcadores possuírem dupla realidade: visual e prosódica; seu reconhecimento requer certas especificidades se compararmos com o reconhecimento de outras palavras.

Diante de nossos questionamentos e da hipótese levantada, nossos objetivos são:

a) avaliar a adequação ou não da arquitetura comumente usada para explicar o processamento da fala no processamento dos MPGs e dos MPLs;

b) avaliar a adequação ou não da arquitetura comumente usada para explicar o processamento da escrita no processamento dos MPGs e dos MPLs;

c) determinar a direção de seu processamento: top-down ou bottom-up;

d) propor, se necessário, ajustes nas arquiteturas avaliadas de sorte a determinar o(s) sistema(s) perceptual(is) envolvidos no processamento do marcadores prosódicos.

Para dar conta de nossos objetivos, avaliaremos as arquiteturas de processamento da fala e da escrita, buscando determinar qual(is) sistema(s) perceptual(is) está(ão) efetivamente envolvido(s) no processamento dos marcadores .

Com os resultados obtidos nesta pesquisa, seremos capazes de compreender a forma como os marcadores prosódicos são processados, abrindo possibilidades para se pensar estratégias de leituras para alunos em fase de aquisição da língua escrita com vistas a torná-los leitores mais fluentes. 


\section{OS SISTEMAS PERCEPTUAIS E O RECONHECIMENTO DOS MARCADORES PROSÓDICOS DA ESCRITA EM SITUAÇÃO DE LEITURA E DE OITIVA: UMA ARQUITETURA POSSÍVEL}

Durante o processo de leitura, o leitor, a partir de um estímulo visual, qual seja, o texto impresso, deverá extrair a mensagem nele contida. Essa extração da mensagem ocorre a partir do acesso a sistemas perceptuais de diferentes níveis, ortográfico, fonológico, lexical, sintático e semântico, contextual, como podemos visualizar a partir da figura 1:

Figura 1 - Estrutura geral para o processamento lexical, conforme proposta de Seidenberg; McClelland

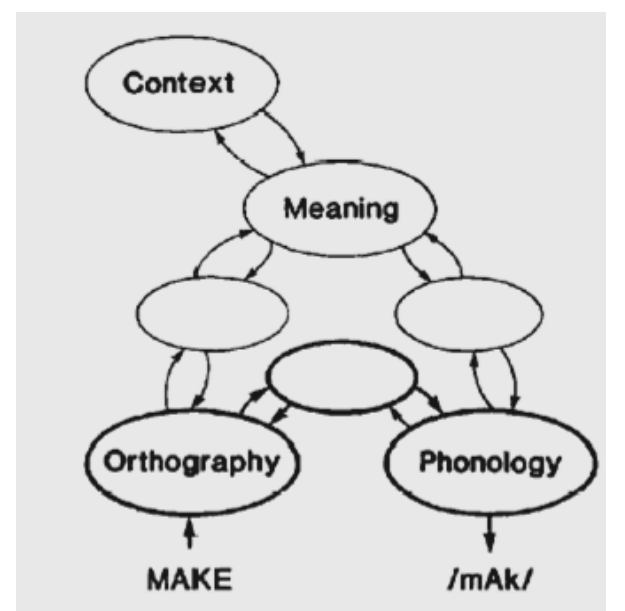

Fonte: Seidenberg; McClelland (1989, p.526).

Durante a oitiva de um texto, o processamento das mensagens tende a partir da mesma estrutura, exceto pelo nível ortográfico que não será acessado, pois o estímulo é auditivo e não visual.

Focando nosso olhar especificamente para a compreensão dos marcadores prosódicos da escrita, os MPGs e os MPLs, sabemos que os sujeitos são capazes de identificar, nos perceptos visual (forma escrita) e auditivo (oitiva de um texto) que lhes são apresentados, mensagens prosódicas que caracterizam os diferentes marcadores (PACHECO, 2007b).

De acordo com Pacheco (2007a), em condição experimental de oitiva de texto, os ouvintes captaram significativamente as variações acústicas do sinal sonoro que lhe chegou ao ouvido e identificaram variações melódicas passíveis de serem associadas no texto escrito a uma palavra ou a um sinal de pontuação. Considerando que, nesse exato momento, o ouvinte foi capaz de identificar uma mensagem no sinal acústico, a condição necessária para o reconhecimento de um marcador prosódico da escrita foi atendida. Assim, temos o reconhecimento de um marcador prosódico da informação auditiva para a informação visual.

O reconhecimento desses marcadores no sentido inverso, qual seja, da informação visual para a informação auditiva, também foi investigado por Pacheco (2007a). Segundo essa autora, o estímulo impresso leva o leitor/ ouvinte a extrair cargas semânticas, no caso dos MPLs, e sentido convencionalizado, no caso dos MPGs, que 
levam esse leitor/ouvinte a realizar mentalmente padrões prosódicos específicos muito comuns na fala. Nesse momento, é extraída uma mensagem prosódica do estímulo visual, estabelecendo, assim, o reconhecimento de um marcador prosódico.

Os resultados obtidos por Pacheco (2007a) evidenciam que o reconhecimento dos marcadores prosódicos pode ocorrer tanto na direção da representação auditiva para a representação visual (escrita), quanto da representação visual para a representação auditiva.

A dupla direção atestada no reconhecimento dos marcadores prosódicos está presente também na relação ortografia e fonologia. Segundo Ziegler e Ferrand (1998), um acoplamento entre esses dois níveis constitui um mecanismo geral presente não somente na percepção visual da palavra, mas também na sua percepção auditiva. Para esses autores, a palavra auditiva influencia o reconhecimento da palavra escrita, bem como a palavra escrita influência na auditiva.

A bidirecionalidade que caracteriza o processo de reconhecimento dos marcadores prosódicos da escrita é uma evidência de que o processamento das informações contidas nos perceptos auditivos e visual, à semelhança do reconhecimento da fala, envolve a participação de diferentes sistemas perceptuais, cuja integração parte dos mecanismos bottom-up (de baixo para cima, feedforward) e top-down (de cima para baixo, feedback).

A bidirecionalidade que caracteriza o processo de reconhecimento dos marcadores prosódicos da escrita é uma evidência de que o processamento das informações contidas nos perceptos auditivos e visual, à semelhança do reconhecimento da fala, envolve a participação de diferentes sistemas perceptuais, cuja integração parte dos mecanismos bottom-up (de baixo para cima, feedforward) e top-down (de cima para baixo, feedback), que são as bases dos modelos de reconhecimento de fala e no processamento de leitura (NORIS; MCQUEEN; CUTLER, 2000; BOWERS, DAVIS, 2004).

De um modo geral, esses modelos assumem que os sistemas perceptuais se organizam hierarquicamente das menores unidades para unidades maiores. Nesse sentido, esses sistemas, para a grande maioria desses modelos, encontram-se organizados como apresentado na figura 2:

Figura 2 - Esquema representativo da organização mínima dos sistemas perceptuais encontrada em modelos de reconhecimento de fala do tipo bottom-up e top-down

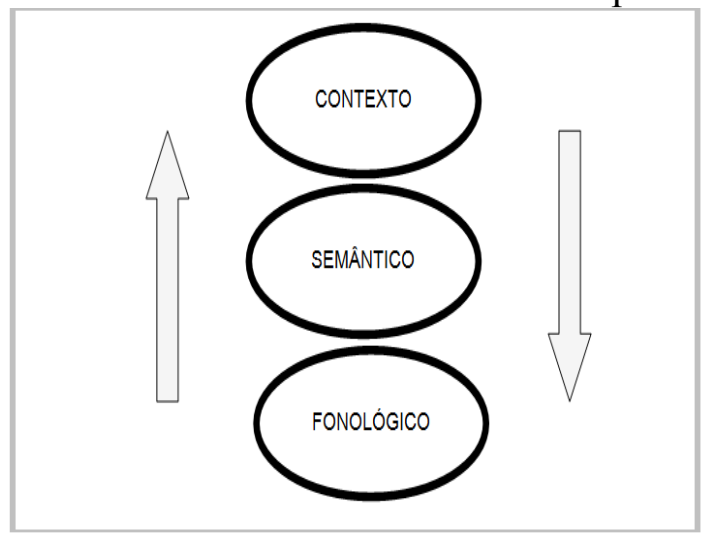

Fonte: Elaboração própria. 
A nossa hipótese e proposta é a de que no processo de reconhecimento dos marcadores prosódicos, a composição dos sistemas perceptuais envolvidos não pode ser exatamente a mesma que está presente no reconhecimento da fala, como apresentado na figura 2. Dada à natureza visual dos marcadores prosódicos, o input inicial não é somente o fonológico. Assim, a composição dos sistemas perceptuais para 0 reconhecimento dos marcadores prosódicos da escrita não deverá ter como sistema perceptivo mais baixo o sistema fonológico, mas, sim, informações visuais que tanto contemplam a palavra escrita quanto as marcas gráficas, respectivamente, para MPL e MPG.

Esse sistema perceptivo visual também não pode ser o mesmo encontrado nos modelos de processamento da leitura. Nesses modelos, o input visual considera somente os aspectos ortográficos da palavra, conforme figura 1 (SEIDENBERG; MCCLELLAND, 1989, entre outros), não contemplando outras informações impressas como os sinais de pontuação.

Considerando que os marcadores prosódicos têm, além de uma realidade visual, uma realidade auditiva, o modelo de reconhecimento de marcadores prosódicos deverá ainda apresentar um sistema perceptual auditivo.

Além desses ajustes, é necessário indicar que, no sistema perceptivo semântico, há um acesso instantâneo a uma informação prosódica que também acessa instantaneamente uma informação semântica, no caso dos MPLs, e um sentido convencionalizado, no caso dos MPGs. Assim, é possível expressar a estreita relação existente entre prosódia e sentido que há nos marcadores prosódicos da escrita que se estabelece durante a leitura.

Com esses ajustes, o esquema representativo da organização dos sistemas perceptuais, derivado do esquema para o reconhecimento da fala e do processamento de leitura, para o reconhecimento dos marcadores prosódicos da escrita apresenta a disposição como propomos na figura 3:

Figura 03 - Esquema representativo da organização dos sistemas perceptuais adaptada para o reconhecimento de marcadores prosódicos da escrita.

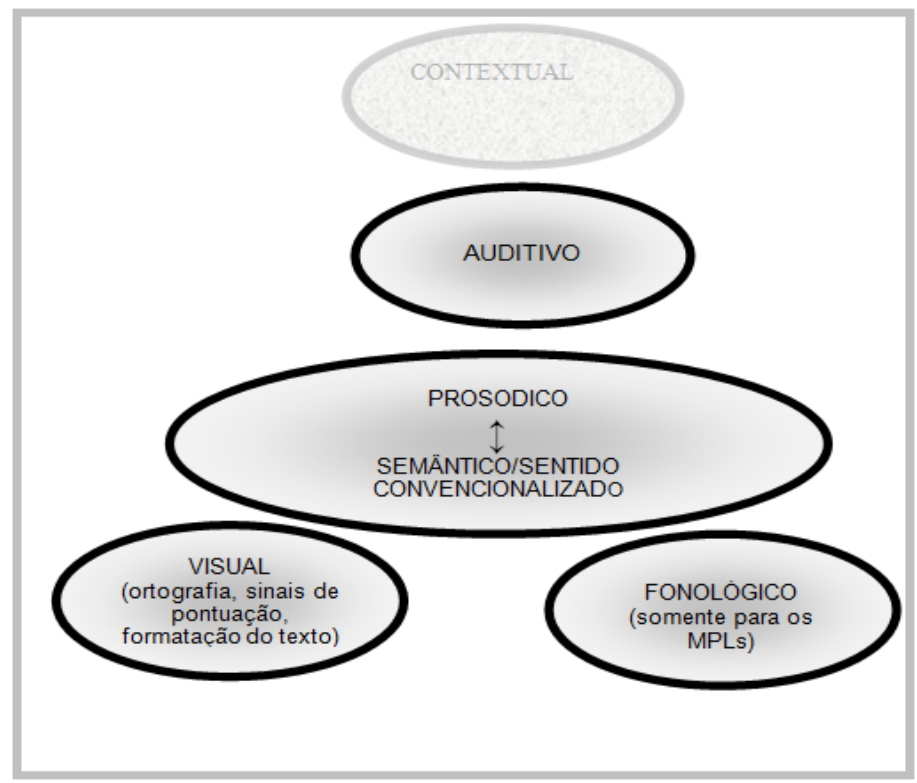

Fonte: Elaboração própria. 
Os sistemas perceptuais como propomos na figura 03 expressam a dupla realidade dos marcadores prosódicos da escrita: visual e auditiva, além de evidenciar que o acesso à semântica e ao sentido convencionalizado, acessa automaticamente uma informação prosódica que lhe está necessariamente atrelada e vice-versa.

Os resultados obtidos por Pacheco (2007a) não mostram a atuação do sistema "Contexto", presente na arquitetura original, no reconhecimento dos marcadores prosódicos da escrita, bem como não traz evidências empíricas que autorizem a retirada definitiva desse sistema da arquitetura dos marcadores.

Diante disso, a solução sugerida por nós é desativar esse sistema, deixando-o aparentemente vazio, à semelhança do arcabouço conexionista de processamento lexical proposto por Seidenberg e McClelland (1989), que prevê espaços vazios entre os códigos de ortografia, sentido e contexto.

Dessa forma, o sistema perceptual contexto, na arquitetura dos marcadores, deve manter-se desativado até que designs experimentais especificamente delineados para essa questão possam fornecer evidências para a ativação e manutenção desse sistema ou evidências para a sua retirada definitiva da arquitetura.

\section{SENTIDO DE ACESSO ÀS INFORMAÇÕES DOS SISTEMAS PERCEPTUAIS NO RECONHECIMENTO DOS MARCADORES PROSÓDICOS DA ESCRITA: PROCESSO INTERATIVO}

Uma vez definida uma arquitetura provável de reconhecimento dos marcadores prosódicos da escrita, tal como apresentamos na figura 3, é preciso estabelecer a forma como as informações que chegam pelos perceptos são processadas e estabelecer o sentido de acesso às informações dos sistemas perceptuais, que como veremos é bidirecional, evidência de que se trata de um processo interativo (bottom-up e topdown) como propomos e expomos na figura 5.

A bidirecionalidade que caracteriza o processo de reconhecimento dos marcadores prosódicos da escrita é uma evidência de que o processamento das informações contidas nos perceptos auditivos e visual, à semelhança do reconhecimento da fala, envolve a participação de diferentes sistemas perceptuais, cuja integração parte dos mecanismos bottom-up (de baixo para cima, feedforward) e top-down (de cima para baixo, feedback), que são as bases dos modelos de reconhecimento de fala e no processamento de leitura. Assim, aqueles que têm por base o mecanismo bottom-up são considerados modelos autônomos ou modulares e aqueles que têm por base o mecanismo top-down são considerados modelos interativos (NORIS; MCQUEEN; CUTLER, 2000; BOWERS, DAVIS, 2004).

Considerando que o sinal sonoro do input auditivo desencadeia o acesso à informação prosódica, verificamos que o acesso a essa informação aciona automaticamente uma carga semântica e um sentido convencionalizado que, por sua vez, acessa uma palavra escrita ou uma marca gráfica, como pode ser visualizado no esquema abaixo: 
Figura 4 - Esquema representativo de reconhecimento de marcadores prosódicos a partir do input auditivo.

\author{
INPUT AUDITIVO $\rightarrow$ INFORMAÇÃO PROSÓDICA $\rightarrow$ CARGA \\ SEMÂNTICA/SENTIDO CONVENCIONALIZADO $\rightarrow$ PALAVRA ESCRITA OU \\ MARCA GRÁFICA
}

Fonte: Elaboração própria.

Dessa forma, o processo de reconhecimento dos marcadores prosódicos pode iniciar no sistema de percepção do nível mais alto, sistema perceptual auditivo, indo para os níveis mais baixos, o que evidencia um processo de reconhecimento do tipo topdown, em que há uma retroalimentação (feedeback) de informações entre os sistemas de percepção.

Assim, o acesso às informações do sistema prosódico/semântico-sentido convencionalizado ocorre em função da informação fornecida pelo sistema perceptual de nível mais alto, assim como o acesso à informação do sistema visual ocorrerá a partir da informação proveniente do sistema acima dele.

O sentido top-down de acesso às informações, no processo de reconhecimento dos marcadores prosódicos consegue explicar com certa eficácia a associação significativa encontrada entre estímulo auditivo e a palavra escrita e marcas gráficas com carga semântica e sentido convencionalizado, indicadores de variação prosódica.

Esse tipo de acesso é também reportado na literatura para o reconhecimento de

fonemas. Resultados experimentais fornecem fortes evidências de que o reconhecimento dessas unidades pode ocorrer a partir do nível lexical, que é um nível superior ao nível fonológico (MORTON; LONG, 1976; RUBIN; TURVEY; van GELDER, 1976; FOSS; BLANK, 1980; GANONG, 1980; CUTLER ET AL., 1987; MEHLER; SEGUÍ, 1987; SAMUEL,1981; 1987; 1996).

$\mathrm{O}$ acesso às informações durante o processamento da fala não ocorre unicamente no sentido top-down, mas também no sentido bottom-up, ou seja, de baixo para cima.

Esse tipo de processamento é verificado em situações nas quais a escolha lexical é comprometida pela exposição de um ouvinte a um estímulo danificado. Assim, o acesso à informação lexical ocorrerá a partir das informações do nível fonológico que as associará às informações lexicais (CUTLER; NORRIS, 1979; CUTLER et al. 1987).

Uma outra evidência para o acesso bottom-up, no processo de reconhecimento da fala, são as ocorrências dos lapsos langue na fala. Os lapsos langue são trocas de segmentos automáticas e não planejadas pelo falante, produzindo uma outra palavra diferente daquela que, pelo contexto, deveria de fato ser dita.

Para que essa troca de segmentos ocorra, é provável que informações do nível fonológico estejam influenciando o acesso das informações do nível lexical, havendo uma interferência de baixo para cima, gerando, nessa situação em particular, um reconhecimento lexical diferente e inesperado.

Evidências de um acesso de informações do tipo bottom-up igualmente são encontradas no reconhecimento dos marcadores prosódicos da escrita. Durante o processo de leitura, diante do texto escrito, os indivíduos tendem a atribuir um padrão auditivo às palavras que indicam modos de falar e as marcas gráficas que representam os sinais de pontuação, compatível com a sua carga semântica e com o seu sentido convencionalizado, respectivamente (PACHECO, 2007a). 
A alta correspondência encontrada por Pacheco (2007a) entre as informações visual e auditiva dos marcadores, a partir de um input visual (texto escrito), indica que o reconhecimento se deu do sistema perceptual visual, que é mais baixo, para o sistema perceptual auditivo, mais alto, logo, uma direção do tipo bottom-up.

Essas constatações permitem admitir que o processo de reconhecimento dos marcadores prosódicos ocorra nas duas direções, ascendente e descendente, e que o acesso aos sistemas perceptuais ocorrem de forma paralela e simultânea. Assim, o modelo interativo descreve com mais exatidão o que ocorre no reconhecimento dos marcadores prosódicos da escrita, como na tarefa de leitura com um todo.

Esse processo contempla tanto a forma ascendente quanto a forma descendente de processamento de informação, o que, de acordo com Navas e Santos (2004), contribui para a compreensão da leitura, haja vista que para ser um bom leitor, é necessário que se tenha uma boa capacidade de reconhecimento visual de palavras, bem como alto nível de conhecimento linguístico conceitual.

Diferentemente dos processos bottom-up e top-down, nos quais o processamento de informação se dá de forma sequencial, o modelo interativo se caracteriza por permitir a ocorrência de processamento paralelo e simultâneo. Assim, não há uma sequência fixa de acontecimento dos estágios: estágios que tendam a ocorrer numa sequência posterior podem ser iniciados antes mesmo que estágios iniciais tenham sido completados (SANTOS; NAVAS, 2004).

Navas e Santos (2004), com base em Catts e Kahmi (1999), admitem que o processo interativo em paralelo ou simultâneo reflete mais adequadamente os tipos de processamento que ocorrem em tarefas que sejam complexas, como é o caso da atividade de leitura. Isso porque, de acordo com as autoras, o processo interativo captura as interações que ocorrem dentro e entre os diversos níveis de processamento.

De acordo com Zimmer, Blatskowski e Gomes (2004), abordagens como a interativa são equilibradoras e sugerem uma interatividade do conhecimento linguístico provenientes de vários níveis de informações tais como ortográficas, fonológicas e semânticas. Assim, para esses autores, a leitura hábil resultaria de uma constante integração entre os processos cognitivos descendentes e os ascendentes.

Um processamento de informações interativo, segundo Grabe (1991 apud ZIMMER; BLATSKOWSKI; GOMES, 2004), busca explicar a leitura como uma atividade de interação que pode se dá através ( $i$ ) da interação entre o leitor e o texto que ativa simultaneamente várias habilidades no processamento da informação; e/ou (ii) por meio da integração de processos cognitivos.

$\mathrm{Na}$ interação leitor/texto, tem-se que o leitor usa o seu conhecimento de mundo para construir o sentido do texto. Já na integração dos processos cognitivos tem-se a integração de um conjunto de habilidades cognitivas que integram o nível básico de processamento como a identificação e decodificação de palavras com o nível de processamento de habilidades de compreensão e raciocínio, como a interpretação e realização de inferências. Nesse sentido, observa-se uma operação conjunta e simultânea na compreensão do texto (GRABE, 1991 apud ZIMMER; BLATSKOWSKI; GOMES, 2004).

Diante das reflexões apresentadas, o esquema organizacional para o reconhecimento dos marcadores prosódicos deverá conter uma seta para cima que indica que o processo ocorre de baixo para cima, e uma outra, apontado para baixo, sinalizando, por sua vez, o sentido de cima para baixo. Nesse processo, o acesso aos sistemas perceptuais ocorre nas duas direções. 
Além disso, setas com dupla direção devem ser acrescentadas ao esquema, indicando que o acesso às informações entre os sistemas perceptuais são contíguos. A condição de mismatch (não coincidência entre informação visual e informação auditiva), avaliada por Pacheco (2007a), evidencia que informações do sistema perceptual auditivo não acessam diretamente informações do sistema perceptual visual. Para acessar as informações do sistema perceptual visual, deverão ser acessadas necessariamente as informações conjugadas variação prosódica/carga semântica-sentido convencionalizado.

A mesma contiguidade de acesso deverá ser observada no sentido ascendente: informações do sistema perceptual visual não acessarão informações do sistema perceptual auditivo sem acessar, necessariamente, as informações do sistema carga semântica-sentido convencionalizado/prosódica, que, por sua vez, acessarão as informações no sistema perceptual auditivo.

Assim, a arquitetura a ser proposta para o processo de reconhecimento dos marcadores prosódicos deverá explicitar o duplo acesso entre os sistemas perceptuais, indicando que um sistema acessa informações do sistema imediatamente acima ou imediatamente abaixo, como é geralmente encontrado em outras arquiteturas, como por exemplo, para processamento de leitura, como a proposta por Ellis e Young (1988); processamento de palavra visual, como a proposta por Seidenberg e McClelland (1989).

Assumindo a dupla direção do acesso às informações dos sistemas perceptuais, bem como o duplo acesso das informações entre os diferentes sistemas perceptuais e, considerando os ajustes dos tipos de sistemas envolvidos no processo de reconhecimento de marcadores prosódicos, como apresentado na figura 03, uma arquitetura possível para explicar esse processo tende a ser como a que formulamos na figura 05.

Figura 05 - Arquitetura proposta para o processo de reconhecimento dos marcadores prosódicos da escrita

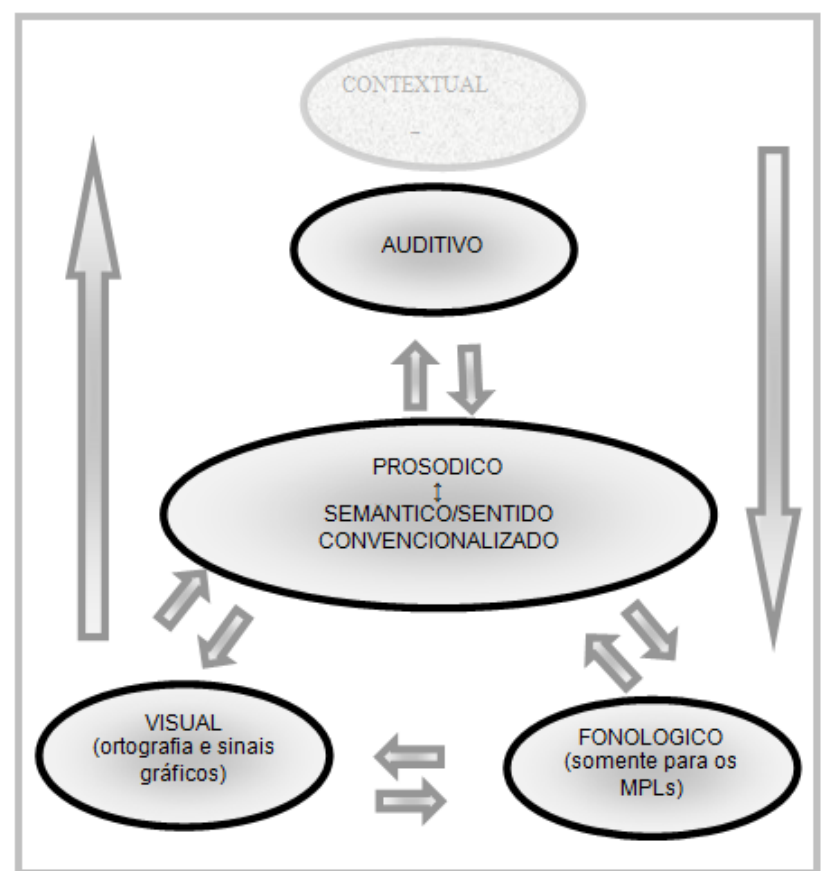

Fonte: Elaboração própria. 


\section{4 À GUISA DE CONCLUSÃO}

Em função da discussão desenvolvida, podemos afirmar que os dois tipos de marcadores, lexicais e gráficos, possuem o mesmo processo de reconhecimento, e que o mesmo é muito similar ao do reconhecimento de fala e do processamento lexical durante a leitura.

O processo de reconhecimento dos marcadores prosódicos traz evidências favoráveis para os modelos de reconhecimento que priorizam os acessos às informações ascendentes e descendentes de forma simultânea. Em conjunto com o reconhecimento da fala, que também tem mostrado ter os dois sentidos, o reconhecimento dos MPGs e dos MPLs tem demonstrado que não é possível assumir que uma única direção esteja operando no acesso às informações, mas, pelo contrário, as duas direções podem concorrer no reconhecimento de um aspecto qualquer da língua.

Os MPGs e dos MPLs abundantes nos textos escritos encontram lugar privilegiado no processo de leitura dada à sua natureza visual (escrita) e oral (indicações de variações prosódicas).

É de se supor que, em uma leitura fluente, acessos ascendentes/descendentes e de forma contígua aos sistemas perceptuais deverão ser realizados.

Em síntese, com o intuito de responder às questões postas neste artigo, podemos afirmar que o reconhecimento dos marcadores prosódicos da escrita ocorre mediante processo top-down e bottom-up, de forma interativa e ajustes na arquitetura default do processamento da fala e da leitura devem ser feitos com vistas a contemplar sua dupla realidade visual e oral.

Com este artigo, apresentamos uma arquitetura de processamento de leitura inédita na literatura que contempla aqueles elementos textuais que trazem para a escrita aspectos prosódicos típicos da fala e que se não realizados a contento comprometem a interpretação do texto.

A arquitetura apresentada traz consequências diretas para o ensinoaprendizagem da leitura, haja vista que estratégias que privilegiam atividades de leitura oral de textos e de oitiva de leitura em voz alta devem ser adotadas para que o aprendiz seja capaz de ter contato tanto com a realidade visual quanto auditiva dos marcadores prosódicos.

Enfim, ler com fluência um texto é resgatar na totalidade todas as informações contidas na materialidade impressa, que vai desde a palavra impressa à própria formatação do texto.

\section{REFERÊNCIAS BIBLIOGRÁFICAS}

BOWERS, J.S.; DAVIS, C.J. Is speech perception modular or interactive? Trends in Cognitive Sciences, v.8, n.1, p. 3-5, jan. 2004.

CAGLIARI, L.C. Marcadores prosódicos na escrita. In: SEMINÁRIO DO GRUPO DE ESTUDOS LINGÜÍSTICOS, 18, 1989, Lorena. Anais do XVIII Seminário do Gel. Lorena: Grupo de Estudos Lingüísticos de São Paulo, 1989. p. 195-203

CATTS, H. W.; KAHMI, A.G. Language and reading disabilities. Boston: Allyn Bacon, 1999, $352 \mathrm{p}$. 
CUTLER, A., et al. Phoneme identification and the lexicon. Cognitive Psychology, v.19, n. 2. p.141-177, 1987.

CUTLER, A.; MELHER, J.; NORRIS, D.; SEGHÍ, J. Phoneme identification and the lexicon. Cognitive Psychology, v.19. p. 141-7, 1987.

ELLIS, A.W.; Young, A.W. Human cognitive neuropsychology. Hove: Lawrence Erlbaum, 1988.

FOSS, D.; J; BLANK, M. A. Identifying the speech codes. Cognitive Psychology, v.12, p. 1-31, 1980 .

GANONG, W. F. Phonetic categorization in auditory word perception. Journal of Experimental Psychology. Human Perception and Performance, v. 6. p. 110-125, 1980.

GRABE, W. Current developments in second language reading research. TESOL Quarterly, v. 25, n. 3, p. 375-406, 1991

MACHADO FILHO, A. M. Lingüistica e humanismo. Petrópolis: Vozes, 1974.

MEHLER, J.; SEGUÍ, J. English and French speech processing. In: The psychophysics of speech perception. In: SCHOUTEN, M.E. H. (Org.). The Psychophysics of speech perception. Dordrecht: Martinus Niijhoff Publishers, 1987. p. 405-418. (Nato Aso, 39).

MORTON, J.; LONG, J. Effect of word transitional probability on phoneme identification. Journal of Verbal Learning and Verbal Behavior, v. 15, p. 43-51, 1976.

MOURÃO, J. A. Introdução. In: PROUST, M. Sobre a leitura. 2.ed. Lisboa: Vega, 1998. p. 5-20.

NORRIS, D.; MCQUEEN J. M.; CUTLER, A. Merging information in speech recognition: Feedback is never necessary. Behavioral and Brain Sciences, v. 23, n. 3, p. 299-370, jun. 2000.

PACHECO, V. Investigação fonético-acústico e experimental dos sinais de pontuação enquanto marcadores prosódicos. Dissertação (mestrado em Lingüística) 132 f. Instituto de Estudos da Linguagem, Unicamp, Campinas: 2003

PACHECO, V. O efeito dos estímulos auditivo e visual na percepção dos marcadores prosódicos usados na escrita do PB. Sínteses, v. 12, p.235-245, 2007 a.

PACHECO, V. Leitura e prosódia: o caso dos sinais de pontuação. In: FONSECASILVA, M.C; PACHECO,V.; LESSA-DE-OLIVEIRA, A.S.C. (Orgs) Em torno da língua(gem): questões e análises. Vitória da Conquista: Edições Uesb, 2007b, p. 41-69.

RUBIN, P.; TURVEY, M. T.; van GELDER, P. Initial phonemes are detected faster in spoken words than in nonwords. Perception and Psychophysics, v. 19, p. 394-398, 1976. 
SAMUEL, A. G. Does lexical information influence the perceptual restoration of phonemes? Journal of Experimental Psychology: General, v 125 , p. 28-51, 1996.

SAMUEL, A. G. Lexical uniqueness effects on phonemic restoration. Journal of Memory and Language, . v. 26, p. 36-56, 1987.

SAMUEL, A. G. Phonemic restoration: Insights from a new methodology. Journal of Experimental Psychology: General, v. 110, p. 474-494, 1981.

SANTOS, M.T.M; NAVAS; A. L.G.P. Aquisição e desenvolvimento da linguagem escrita. In:

2004, p. $225-261$

SEIDENBERG, M.S., MCCLELLAND, J.L. A distributed, developmental model of visual word recognition and naming. Psychological Review, v. 96, p. 523-568, 1989. WITHNEY, W.D. Languagen and the study language. Paris: la vie du lanage, 1875

ZIEGLER, J. C., FERRAND, L. Orthography shapes the perception of speech: The consistency effect in auditory word recognition. Psychonomic Bulletin \& Review, v. 5, p. 683-689, 1998.

ZIMMER, M.C., BLASKOWSKI, M.J., GOMES, N.M.T. Desvendando os sentidos do texto: cognição e estratégias de leitura. Nonada, n.7, p. 97- 128, 2004.

Recebido em: 31 de março de 2014.

Aceito em: 12 de maio de 2014. 